\title{
PERFORMANCE ANALYSIS OF TRANSMISSION OF 5 USERS BASED ON MODEL B USING GF (5) WITH VARYING BIT RATES FOR 3D OCDMA SYSTEM
}

\author{
Shilpa Jindal ${ }^{1}$ and N Gupta ${ }^{2}$ \\ ${ }^{1,2}$ Department of Electronics Electrical and Communication Engineering, \\ PEC University of Technology, Sector 12, Chandigarh, India. \\ ${ }^{1}$ ji_shilpaeyahoo.co.in
}

\begin{abstract}
We present transmission of five users with $5 W D M \times 4 T D M \times 5$ CODE channel on $3 D$ OCDMA system based on Model B using GF (5) with varying receiver attenuation at 1Gbps, 2 Gbps, 5 Gbps and 10Gbps data rates on OPTSIM.

\section{KEYWORDS}

Optical Code Division Multiple access, Optical Orthogonal Codes(OOC), linear congruent operator, cubic congruent operator, Galois field (5), 3 Dimensional, Model B.
\end{abstract}

\section{INTRODUCTION}

Coding schemes play a major role in analyzing the performance of OCDMA system. In this direction many researchers have proposed signature sequences in different dimensions $[2,7,11$, and 12]. We had modeled these sequences based on algebraic coding theory in two categories Model A and Model B [1, 3, 4, and 5].

In this paper we have used the OPTSIM simulation tool to evaluate the performance of transmission of five users based on Model B using optical orthogonal codes, Cubic Congruent Operator and Linear Congruent Operator from algebra theory with varying bit rates. The paper is organized as follows. In Section II, Mathematical Modeling of 3D OCDMA system along with Model B is discussed. Section III shows the 3D Codeset and calculates the system parameters required for simulation. Section IV shows the implementation details on the simulation software along with the results for five users with $5 \mathrm{WDM} \times 4 \mathrm{TDM} \times 5$ CODE Channel 3D OCDMA system based on Model B using GF (5) with varying attenuation at the front end of the receiver at variable bit rates. Finally conclusion is drawn in section $\mathrm{V}$.

David C. Wyld (Eds) : ICCSEA, SPPR, CSIA, WimoA - 2013

pp. 97-106, 2013. @ CS \& IT-CSCP 2013

DOI : $10.5121 /$ csit.2013.3510 


\section{MATHEMATICAL MODEL}

In Model $\mathrm{B}$, OOC code is used to spread in time domain and is taken from literature $\mathrm{C}=$ 1011000100000 is a $(13,4,1)$ code with $\mathrm{c}=\{0,2,3,7\}$ where $\mathrm{n}=13, \mathrm{w}=4$ and $\lambda \mathrm{a}=\lambda \mathrm{c}=1$, coding scheme of cubic congruent operator based on Table 1 is used for spreading in spectral domain and coding scheme of linear congruent operator is used for spreading in spatial domain as shown in Fig 1. The multiplicative inverse for GF (5) and. Cubic and linear Algebraic Congruent operators values are given in table 1 and are defined by following equations [6]

$$
\begin{aligned}
& \left.s_{m}(n, a, b)=\left(m(a+n)^{3}+b\right)\right)(\bmod p) \quad \mathrm{a}=\mathrm{b}=0 \quad \text { Cubic Congruent Operator Eq } 1 \\
& s_{m}(n, a, b)=[m \cdot(n \cdot a+b)][(\bmod p)] \mathrm{a}=1 \quad \& \quad \mathrm{~b}=0 \text { Linear Congruent Operator Eq } 2
\end{aligned}
$$

Where $\mathrm{n}$ and $\mathrm{m}$ are the indexes and elements of the Galois field and their values are expanded in Table 1.

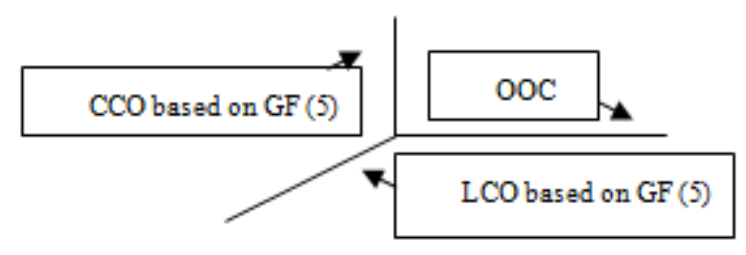

Fig. 1: Model B [1]

Table 1. Multiplicative Inverses for GF (5) and Sequences over GF (5) using cubic Algebraic Congruent operator and linear algebraic congruent operator

\begin{tabular}{|c|c|c|c|c|c|}
\hline$\times$ & 0 & 1 & 2 & 3 & 4 \\
\hline 0 & 0 & 0 & 0 & 0 & 0 \\
\hline 1 & 0 & 1 & 2 & 3 & 4 \\
\hline 2 & 0 & 2 & 4 & 1 & 3 \\
\hline 3 & 0 & 3 & 1 & 4 & 2 \\
\hline 4 & 0 & 4 & 3 & 2 & 1 \\
\hline
\end{tabular}

\begin{tabular}{|l|l|l|l|l|l|}
\hline $\mathrm{m}, \mathrm{n}$ & 0 & 1 & 2 & 3 & 4 \\
\hline 0 & 0 & 0 & 0 & 0 & 0 \\
\hline 1 & 0 & 1 & 3 & 2 & 4 \\
\hline 2 & 0 & 2 & 1 & 4 & 3 \\
\hline 3 & 0 & 3 & 4 & 1 & 2 \\
\hline 4 & 0 & 4 & 2 & 3 & 1 \\
\hline
\end{tabular}

\begin{tabular}{|l|l|l|l|l|l|}
\hline $\mathrm{m}, \mathrm{n}$ & 0 & 1 & 2 & 3 & 4 \\
\hline 0 & 0 & 0 & 0 & 0 & 0 \\
\hline 1 & 0 & 1 & 2 & 3 & 4 \\
\hline 2 & 0 & 2 & 4 & 1 & 3 \\
\hline 3 & 0 & 3 & 1 & 4 & 2 \\
\hline 4 & 0 & 4 & 3 & 2 & 1 \\
\hline
\end{tabular}

\section{3D CODESET AND OCDMA SYSTEM}

In accordance with Model B shown in Fig 1, the signature sequence is spreaded as follows. For temporal spreading: Optical orthogonal code is taken from literature $\mathrm{C}=1011000100000$ is a $(13,4,1)$ code with $c=\{0,2,3,7\}$ where $n=13, w=4$ and $\lambda \mathrm{a}=\lambda \mathrm{c}=1$.here, $\mathrm{n}$ denotes length of the codeword, $w$ is the weight of the codes and $\lambda \mathrm{a} \& \lambda \mathrm{c}$ denotes auto correlation and cross correlation constant [10]. For spectral hopping: codes from cubic congruent operator as calculated in Table 1, from algebra theory are taken based on GF (5) and for spatial encoding codes from linear congruent operator are taken based on GF (5) using Model B. These codes are expanded in Table 3 . 
Table 2. Encoder and Decoder time delay values for variable bit rate systems

\begin{tabular}{|l|l|l|l|l|}
\hline Data rate & $1 \mathrm{Gbps}$ & $2 \mathrm{Gbps}$ & $5 \mathrm{Gbps}$ & $10 \mathrm{Gbps}$ \\
\hline bit period & $1 \mathrm{e}-9$ & $.5 \mathrm{e}-9$ & $.2 \mathrm{e}-9$ & $.1 \mathrm{e}-9$ \\
\hline Time Slot & 13 & 13 & 13 & 13 \\
\hline Chip peiod & $.0769 \mathrm{e}-9$ & $.0384 \mathrm{e}-9$ & $.0153 \mathrm{e}-9$ & $.0076 \mathrm{e}-9$ \\
\hline TD t $_{0} \mathrm{E}$ & 0 & 0 & 0 & 0 \\
\hline TD t $_{2} \mathrm{E}$ & $.1538 \mathrm{e}-9$ & $.0768 \mathrm{e}-9$ & $.0306 \mathrm{e}-9$ & $.0152 \mathrm{e}-9$ \\
\hline $\mathrm{TD} \mathrm{t}_{3} \mathrm{E}$ & $.2307 \mathrm{e}-9$ & $.1152 \mathrm{e}-9$ & $.0459 \mathrm{e}-9$ & $.0228 \mathrm{e}-9$ \\
\hline TD t $_{7} \mathrm{E}$ & $.5384 \mathrm{e}-9$ & $.2688 \mathrm{e}-9$ & $.1071 \mathrm{e}-9$ & $.0532 \mathrm{e}-9$ \\
\hline TDt $_{13} \mathrm{D}$ & $.9997 \mathrm{e}-9$ & $.4992 \mathrm{e}-9$ & $.1989 \mathrm{e}-9$ & $.0988 \mathrm{e}-9$ \\
\hline $\mathrm{TD}_{11} \mathrm{D}$ & $.8459 \mathrm{e}-9$ & $.4224 \mathrm{e}-9$ & $.1683 \mathrm{e}-9$ & $.0836 \mathrm{e}-9$ \\
\hline TDt $_{10} \mathrm{D}$ & $.7690 \mathrm{e}-9$ & $.3840 \mathrm{e}-9$ & $.1530 \mathrm{e}-9$ & $.076 \mathrm{e}-9$ \\
\hline TDt $_{5} \mathrm{D}$ & $.4614 \mathrm{e}-9$ & $.2304 \mathrm{e}-9$ & $.0918 \mathrm{e}-9$ & $.0456 \mathrm{e}-9$ \\
\hline
\end{tabular}

Table 3. Code Sequences

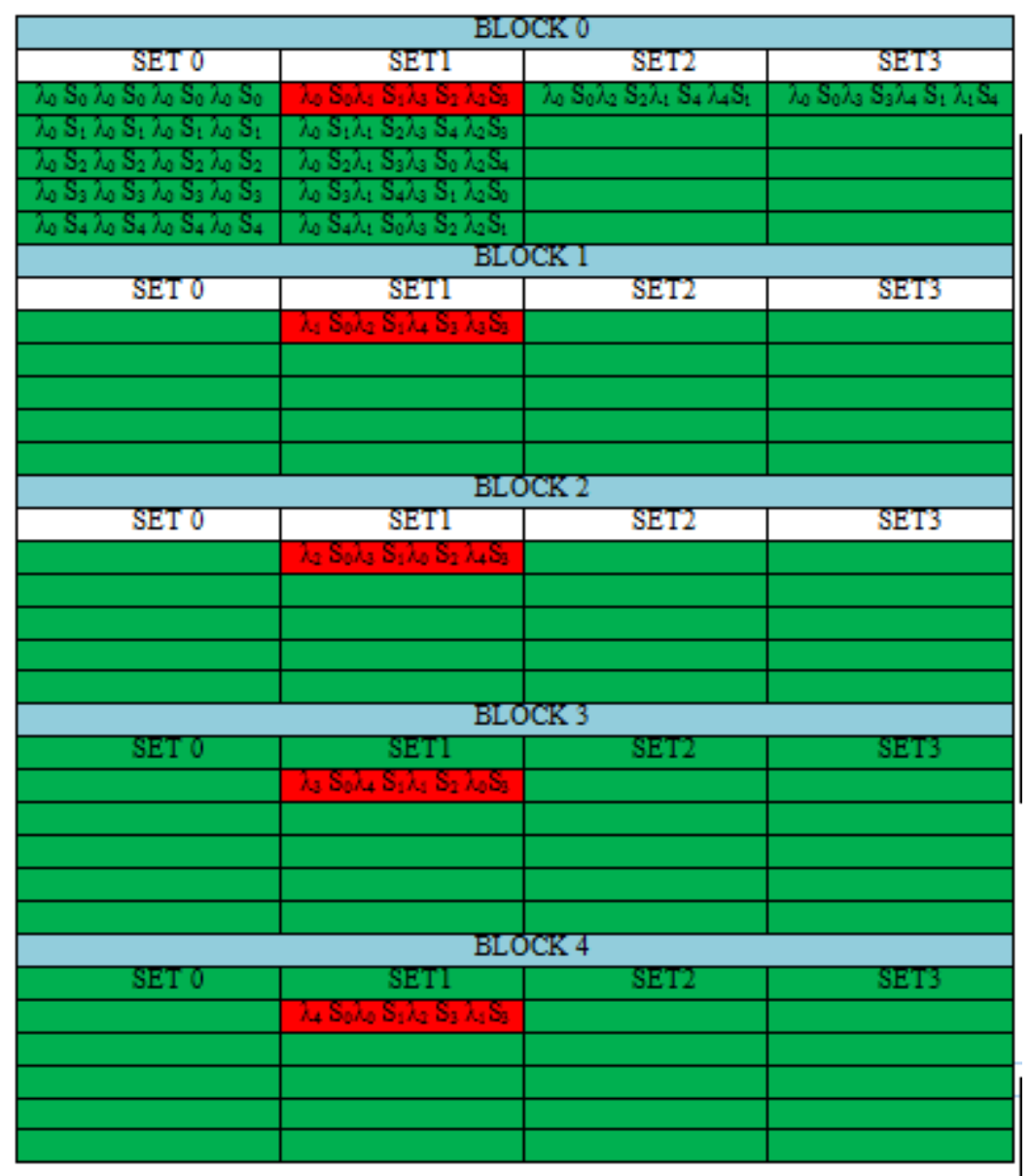


Table 4. System Parameters [6]

\begin{tabular}{|l|l|l|}
\hline S.No. & Parameter & value \\
\hline 1 ) & Bit rate & $1,2,5$ and10e9 \\
\hline 2 ) & Bit period & Variable (Table2) \\
\hline 3$)$ & Chip period & Variable ( Table2) \\
\hline 4$)$ & Time slot & 13 \\
\hline 5$)$ & Laser wavelength & $\begin{array}{c}\lambda_{1}=1550.0 \mathrm{e}-9 \mathrm{~m} \text { to } \\
\lambda_{s}=1553.2 \mathrm{e}-9 \mathrm{~m}\end{array}$ \\
\hline 6$)$ & Rep rate of source & Variable( Table2) \\
\hline 7$)$ & Peak power of laser & $1.0 \mathrm{e}-3 \mathrm{w}$ \\
\hline 8$)$ & Delta[2] & $.8 \mathrm{e}-9(\mathrm{DWDM})$ \\
\hline 9$)$ & No. of lasers & 5 \\
\hline 10$)$ & Combiner/Mux & $5 \times 1$ \\
\hline 11$)$ & Combiner loss & $3 \mathrm{~dB}$ \\
\hline 12$)$ & Pattern type & PRBS \\
\hline 13$)$ & Pattern length & 7 bits \\
\hline 14$)$ & Fibre Attenuator & Variable in dB \\
\hline
\end{tabular}

Simulation parameters: For 3D OCDMA system design, time delay for encoders and decoders for variable data rate is calculated as under and is summarized in table 2.

The bit rate is taken as $1 \mathrm{Gbps}$ for each channel and time slot is the length of the temporal codes. In this simulation $(13,4,1)$ OOC is taken for spreading in time domain.

Thus the bit period is calculated as:

Bit Period=1/Bit Rate $=1 / 1 \mathrm{e} 9=1 \mathrm{e}-9$ and Chip period=Bit Period $/$ Time Slot $=1 \mathrm{e}-9 / 13=.0769 \mathrm{e}-9$.

Now the time delay lines for temporal code (1011000100000) [8] are calculated as

Time Delay lines for Encoder

$\mathbf{t}_{\mathbf{0}}=0 \times .0769 \mathrm{e}-9=0 ; \quad \mathbf{t}_{\mathbf{2}}=2 \times .0769 \mathrm{e}-9=.1538 \mathrm{e}-9$

$\mathbf{t}_{3}=3 \times .0769 \mathrm{e}-9=.2307 \mathrm{e}-9 ; \quad \mathbf{t}_{7}=7 \times .0769 \mathrm{e}-9=.5384 \mathrm{e}-9$

Inverse delay lines for Decoder

$\mathbf{t}_{13}=13 \times .0769 \mathrm{e}-9=.9997 \mathrm{e}-9 ; \quad \mathbf{t}_{11}=11 \times .0769 \mathrm{e}-9=.8459 \mathrm{e}-9$

$\mathbf{t}_{10}=10 \times .0769 \mathrm{e}-9=.7690 \mathrm{e}-9 ; \quad \mathbf{t}_{6}=6 \times .0769 \mathrm{e}-9=.4614 \mathrm{e}-9$ 


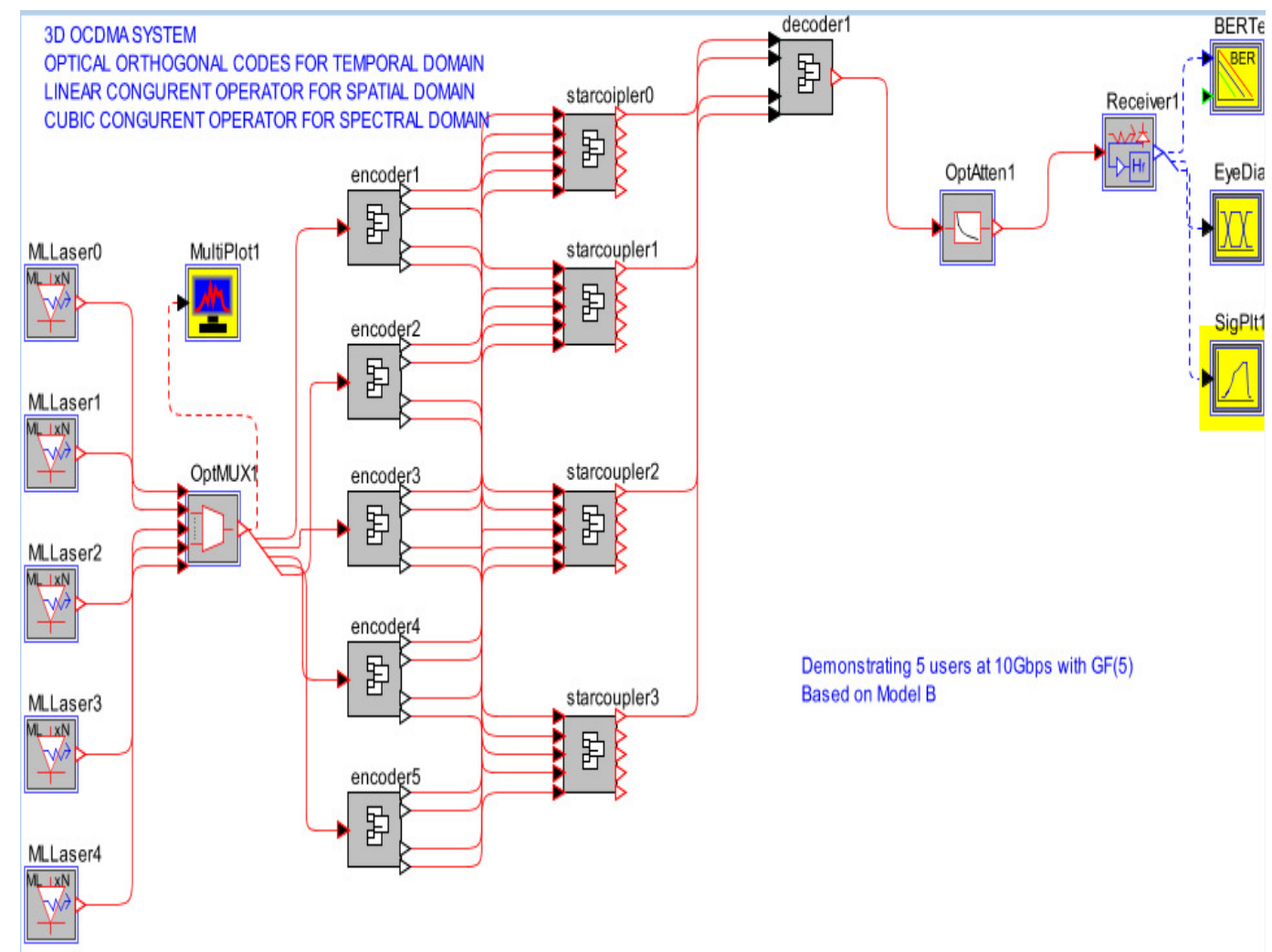

Fig 2: Technology Demonstrator of 3D OCDMA system based on Model B

\section{SIMULATION AND RESULTS}

Table 4 shows the practical parameters that were taken while simulating the proposed 3D codeset based on Model B using cubic and linear congruent operator with GF (5).Proposed System have 5 Operating wavelengths in $C$ band i.e. $\lambda_{1}=1550.0 \mathrm{e}-9 \mathrm{~m}, \lambda_{2}=1550.8 \mathrm{e}-9 \mathrm{~m}, \lambda_{3}=1551.6 \mathrm{e}-9 \mathrm{~m}, \lambda_{4}=$ $1552.4 \mathrm{e}-9 \mathrm{~m}$ and $\lambda_{5}=1553.2 \mathrm{e}-9 \mathrm{~m}$ with variable repetition rate $=1 \mathrm{e} 9,2 \mathrm{e} 9,5 \mathrm{e} 9$ and $10 \mathrm{e} 9$ and peak power $=1.0 \mathrm{e}-3 \mathrm{w}$ of MLL (Laser). And Delta $=.8 \mathrm{e}-9$ (i.e. spacing between the wavelength) is based on Dense Wavelength Division Multiplexing [9]. Fig 2 shows the snapshots of 3D OCDMA, in OPTSIM Simulation Software.

This schematic evaluates the 3D OCDMA link with encoding/ decoding based on Model B with 5 users each transmitting at variable data rate coding based on Galois field GF (5) with cubic and linear congruent operator and optical orthogonal codes.

Fig 3 through 6 shows the signal strength in terms of eye diagram, signal spectrum and auto correlation function at $1 \mathrm{Gbps}, 2 \mathrm{Gbps}$, $5 \mathrm{Gbps}$ and $10 \mathrm{Gbps}$ data rates. These diagrams illustrate that as the bit rate increases from $1 \mathrm{Gbps}$ to $10 \mathrm{Gbps}$ the eye diagram approaches towards close and signal spectrum deteriorates.

The above said signals when passed to 3D OCDMA system results in successful transmission at variable attenuation with data is given in Table 5 through 8 , yellow marks in the table shows minimum and maximum attenuation values and Figures 8 through 11 shows output signal 
strength in terms of eye diagram and signal spectrum with data rates varying from 1 to $10 \mathrm{Gbps}$ with variable attenuation at each data rate.
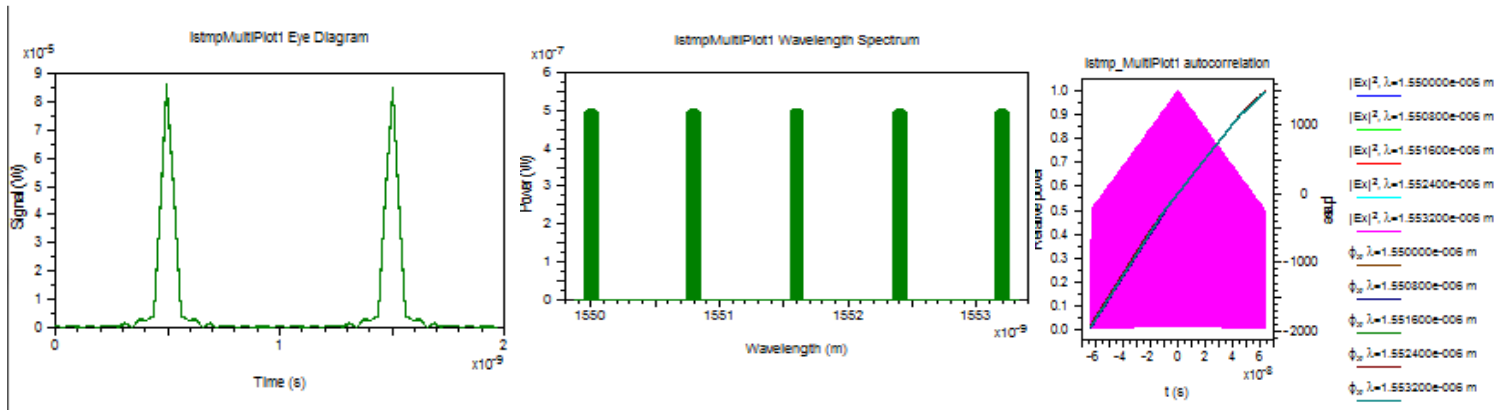

Fig. 3. Input signals: eye diagram, signal spectrum and auto correlation function at $1 \mathrm{Gbps}$
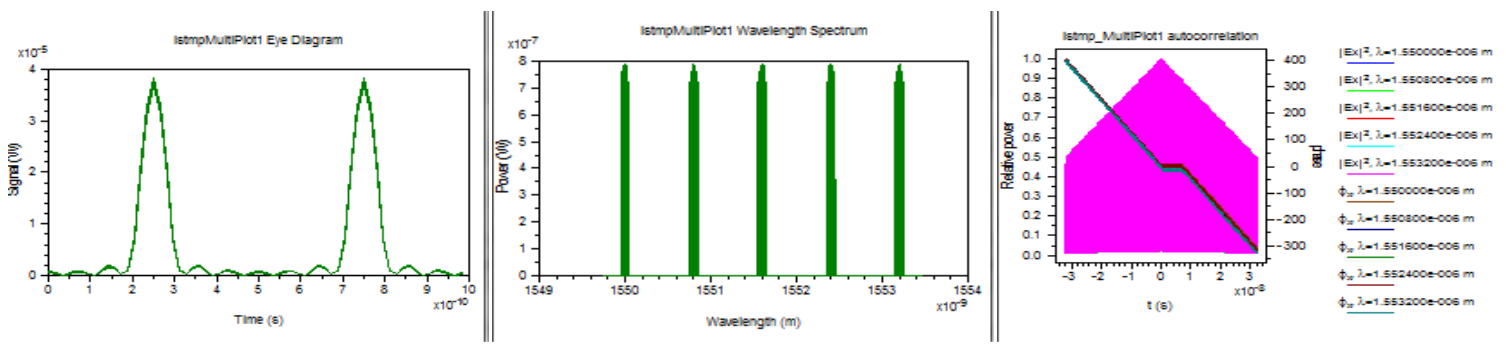

Fig.4. Input signals: eye diagram, signal spectrum and auto correlation function At 2 Gbps
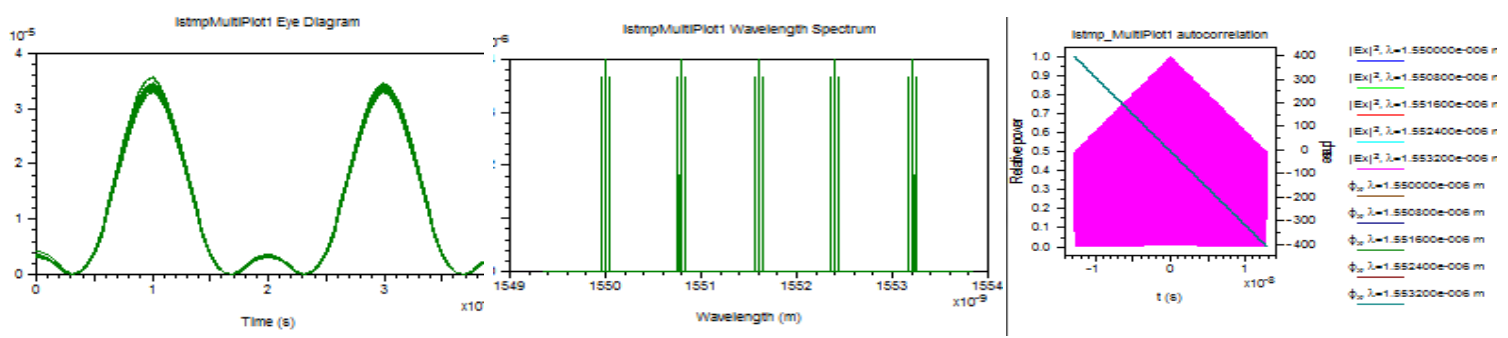

Fig. 5. Input signals: eye diagram, signal spectrum and auto correlation function At 5 Gbps
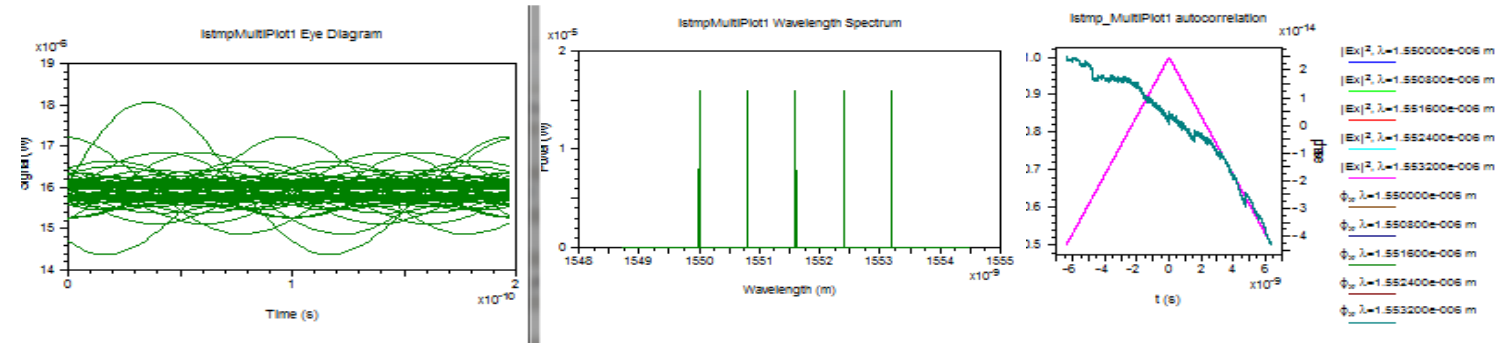

Fig 6: Input signals: eye diagram, signal spectrum and auto correlation function At $10 \mathrm{Gbps}$ 
Table 5. BER v/s Attenuation values at 1 GBPS

\begin{tabular}{|l|l|l|l|l|l|l|}
\hline 5 users & -.2 & -.25 & -.5 & -.1 & -1 & -2 \\
\hline BER & $1.9983 \mathrm{e}-092$ & $2.1730 \mathrm{e}-091$ & $6.0347 \mathrm{e}-083$ & $2.1171 \mathrm{e}-094$ & $2.5980 \mathrm{e}-073$ & $2.4898 \mathrm{e}-005$ \\
\hline
\end{tabular}

Table 6. BER v/s Attenuation values at 2 GBPS

\begin{tabular}{|l|c|c|c|c|c|}
\hline 5 users & -.2 & -.25 & -.5 & -.1 & -1 \\
\hline BER & $4.5609 \mathrm{e}-062$ & $2.8166 \mathrm{e}-061$ & $3.1484 \mathrm{e}-058$ & $1.1249 \mathrm{e}-062$ & $3.2295 \mathrm{e}-053$ \\
\hline & -2 & -2.5 & -5 & -6 & -7 \\
\hline & $4.3917 \mathrm{e}-043$ & $4.2558 \mathrm{e}-038$ & $3.5682 \mathrm{e}-018$ & $6.3758 \mathrm{e}-013$ & $4.0290 \mathrm{e}-009$ \\
\hline
\end{tabular}

Table 7. BER v/s Attenuation values at 5GBPS

\begin{tabular}{|l|l|l|l|l|l|l|l|l|}
\hline 5 users & -.2 & -.25 & -.5 & -.1 & -1 & -2 & -2.5 & -5 \\
\hline BER & $3.0159 \mathrm{e}-014$ & $3.3352 \mathrm{e}-014$ & $5.3649 \mathrm{e}-014$ & $2.4190 \mathrm{e}-014$ & $2.1605 \mathrm{e}-013$ & $3.7118 \mathrm{e}-012$ & $1.7374 \mathrm{e}-011$ & $7.6418 \mathrm{e}-008$ \\
\hline
\end{tabular}

Table 8. BER v/s Attenuation values at 10GBPS

\begin{tabular}{|l|c|c|c|c|c|c|c|}
\hline 5 users & -.2 & -.25 & -.5 & -.1 & -1 & -2 & -2.5 \\
\hline BER & $3.1738 \mathrm{e}-013$ & $3.7543 \mathrm{e}-013$ & $9.2242 \mathrm{e}-013$ & $2.2391 \mathrm{e}-013$ & $5.8913 \mathrm{e}-012$ & $2.6864 \mathrm{e}-010$ & $1.8277 \mathrm{e}-009$ \\
\hline
\end{tabular}

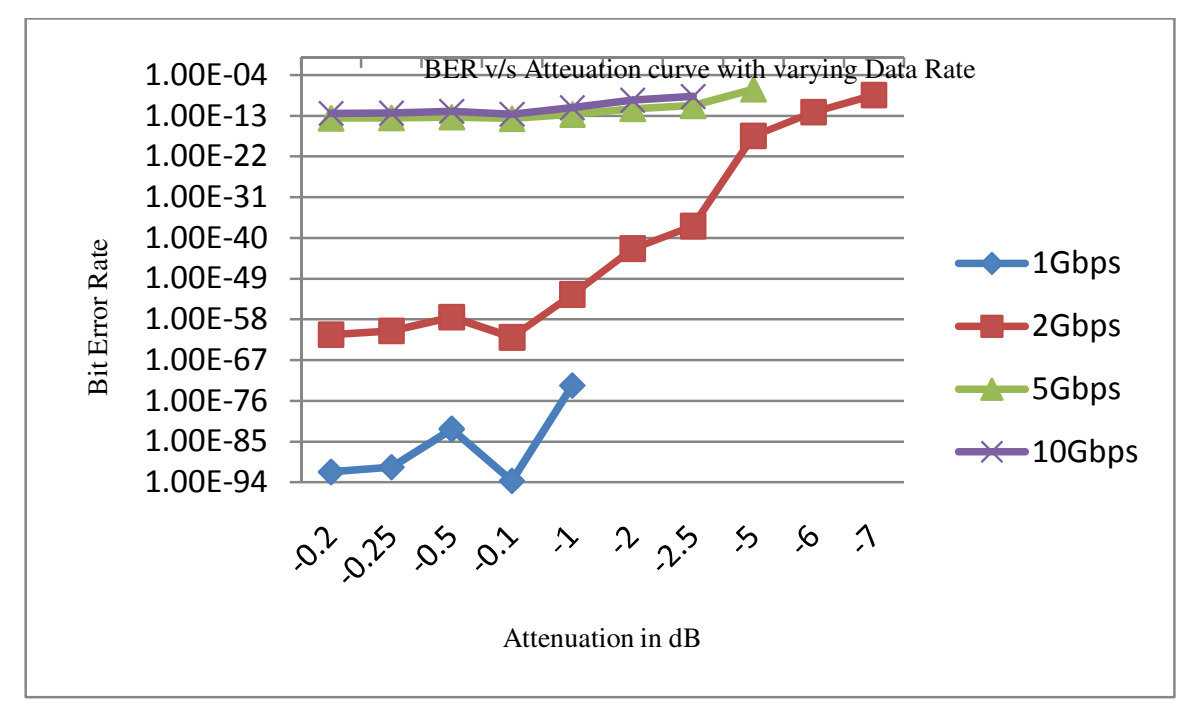

Fig. 7. BER v/s Attenuation curve with varying Data Rate

BER v/s Attenuation curve with varying Data Rate is drawn in Fig 7. As clear from this figure, for each data rate for example at $1 \mathrm{Gbps}$, BER decreases as the attenuation at the front end of the receiver increases shown in blue color, also if the simulation is run for different data rates, BER increases with the increase in data rate with same attenuation. Output signals showing Eye diagram and signal spectrum with variable bit rate and attenuation are shown in Fig 8 through 11. 

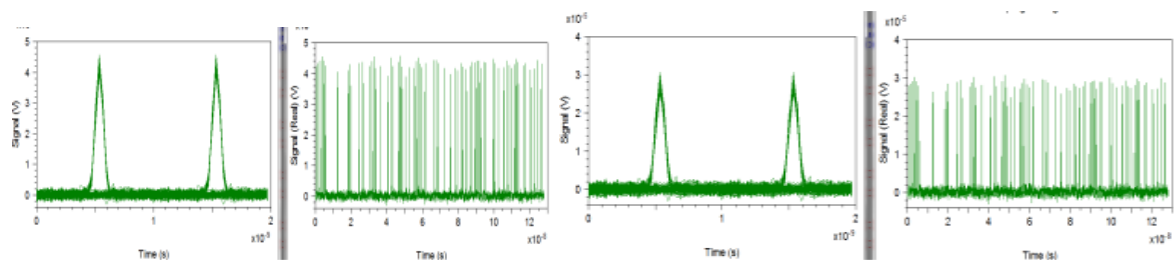

Fig. 8. Eye diagram and signal spectrum At $1 \mathrm{Gbps}$ with attenuation $-.2 \&-2 \mathrm{~dB}$

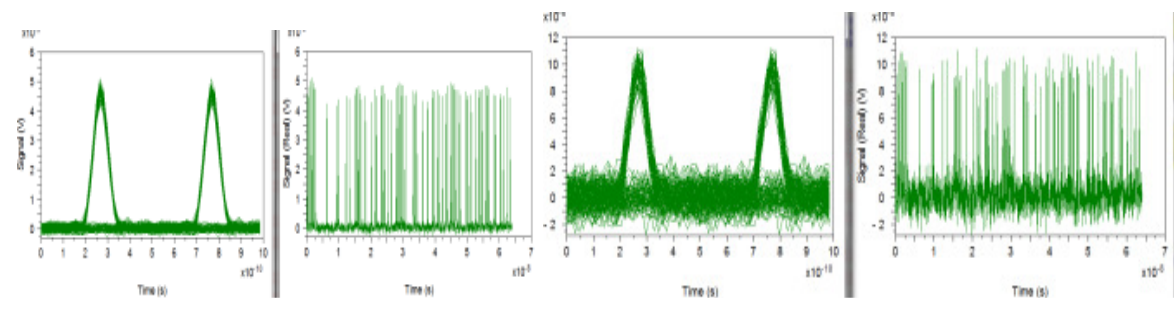

Fig 9. : Eye diagram and signal spectrum At 2 Gbps with attenuation -.2 \&-7dB
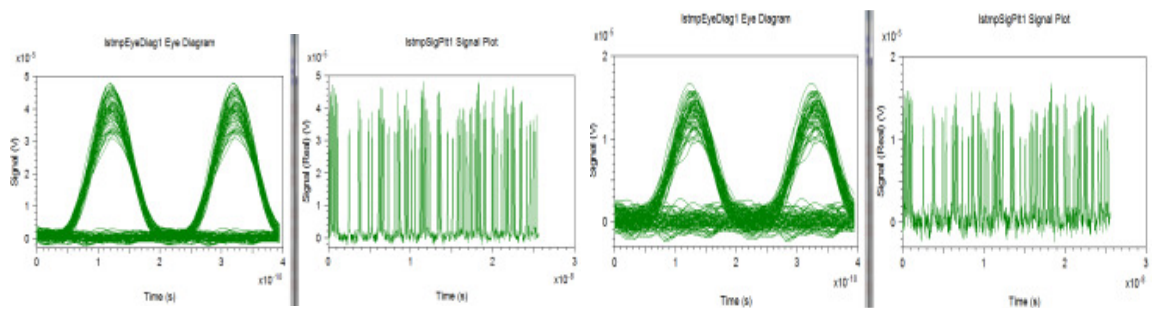

Fig. 10. Eye diagram and signal spectrum At 5 Gbps with attenuation $-.2 \&-5 d B$

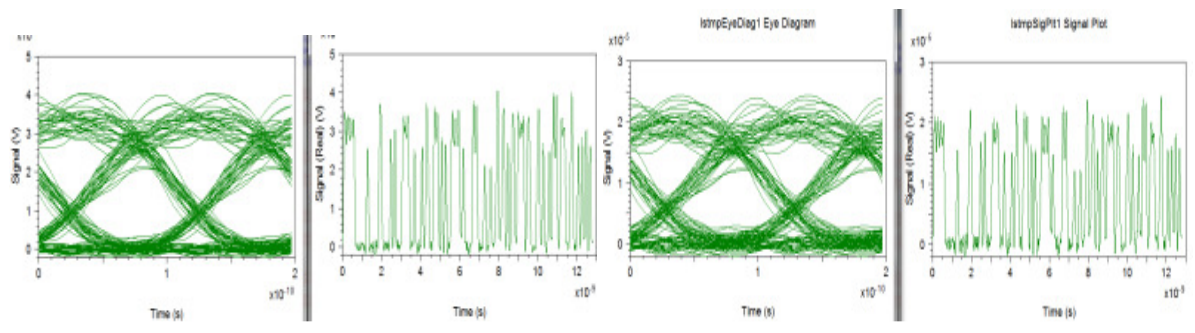

Fig. 11 Eye diagram and signal spectrum At 10 Gbps with attenuation -.2 \&-2.5dB

\section{CONCLUSION}

In this paper we have presented transmission of five users with $5 \mathrm{WDM} \times 4 \mathrm{TDM} \times 5 \mathrm{CODE}$ channel on 3D OCDMA system based on Model B using GF (5) with varying receiver attenuation at $1 \mathrm{Gbps}, 2 \mathrm{Gbps}$, $5 \mathrm{Gbps}$ and $10 \mathrm{Gbps}$ data rate . At $1 \mathrm{Gbps}$, BER decreases as the attenuation at the front end of the receiver increases, for attenuation -.2 dB, Bit Error Rate is $1.9983 \mathrm{e}-092$ and for attenuation of-2dB BER is $2.4898 \mathrm{e}-$ 005 , also if the simulation is run for different data rates, BER increases with the increase in data rate with same value of attenuation. This novel 3D OCDMA System based on code sequences generated trough algebraic operators Supports transmission of maximum of five users with attenuation of-2.5dB at $10 \mathrm{Gbps}$ bit rate with BER $1.8277 \mathrm{e}-009$. 


\section{ACKNOWLEDGEMENT}

We Acknowledge the Optical Communication Lab at Department of Electronics Electrical and Communication Engineering, PEC University of Technology, Sector 12, Chandigarh was this work has been carried out.

\section{REFERENCES}

[1] S. Jindal, N.Gupta, "A New Family of 3D code design using algebraic congruent operator for OCDMA systems.'International Journal of Electronics \& Telecommunication and In-strumentation Engineering (IJETIE) ISSN 0974- 4975, Volume 3, pg 51-58.2010. (IF 2.)

[2] Jawad A Salehi "Code Division Multiple-Access Techniques in Optical Fiber Networks-Part I: Fundamental Principles" IEEE Transactions on Communications, Volume 37, Number. 8, August 1989. Pg $824-833$.

[3] S Jindal, N Gupta "Exploration of Three Dimensional Codes Based on Model A and Model B Using Algebraic Congruent Operator in OCDMA System" International Journal of Mobile \& Adhoc Network, Vol2, issue 3, August 2012. Pg 345-351. ISSN (Online) 2231-6825 ,ISSN (Print) 2249202X Frequency: 4 issues per year Subject Category: Computer Networks Published by: International Forum of Researchers Students and Academi-cian (IFRSA)

[4] S. Jindal, N.Gupta "Analysis of Multi Dimensional Codes for OCDMA System" CiiT In-ternational Journals Print: ISSN 0974 - 9713 \& Online: ISSN 0974 - 9616 (IF 0.569 Impact Factor Calculated using the strict Thompson ISI impact factor methodology from indexing.) Issue:August2012 DOI: NCE082012014

[5] S. Jindal, N.Gupta "Simulated Transmission of five users with $5 \mathrm{WDM} \times 4 \mathrm{TDM} \times 5 \mathrm{CODE}$ at 50 Gbps 3D OCDMA system based on Model B using GF (5)" International Conference on Electrical Engineering and Computer Science (ICEECS) organized By :

IIMT Bhumneshwar, 28th Oct 2012.

[6] Rsoft's OptSim Models Reference Volume II Block Mode, 2010.

[7] Yin "Optical Code Division Multiple Access Communication Networks -Theory and Ap-plications" ISBN 978-3-540-68445-9 Springer year 2009.

[8] Fan R K Chung, Jawed A Salehi and Victor K Wei "Optical Orthogonal Codes: Design, Analysis and Applications" IEEE Transactions on Information Theory, Volume 35, Num-ber. 3, May 1989 Pg 595604.

[9] Govind P Aggarwal ,Lightwave Technology Telecommunication System, Wiley, 2005

[10] Karbassian Phd Thesis "Performance Analysis of Optical Code-Division Multiple-Access (OCDMA) Networks" University of Birmingham May 2009

[11] S. Jindal, N.Gupta "Performance evaluation of optical CDMA based 3D Code with In-creasing Bit Rate in Local Area Network" in IEEE Region 8, SIBIRCON-2008, and Inter-national Conference on "Computational Technologies in Electrical and Electronics Engi-neering" Novosibirsk Scientific Centre, Novosibirsk, Russia, held on July 21-25, 2008. Sponsored by IEEE Region 8, Russia, Pg 386388.

[12] S. Jindal, N.Gupta "Simulated Transmission Analysis of 2D and 3D OOC for Increasing the No. Of Potential users" in 10th Anniversary International Conference on Transparent Optical Networks , ICTON 2008 organized by IEEE Athens, Greece, technical co-sponsorship by IEEE Lasers \& Electro-Optics Society held on June 22-26, 2008” Pg 302-305 . 


\section{Author Biography}

Shilpa Jindal received B.Tech in Electronics and Communication Engineering in year 2003 (Hons.) by securing second position in Punjab Technical University, Jallandhar and Silver Medal thereof. Then she completed M.E. in 2008 from PEC University of Technology (Deemed University), Chandigarh, India. Her current areas of interest are Communication Engineering, Optical Communication, Optical Networks, and Wireless Communication. She Is a Regular Contributor to Various Technical Magazines,

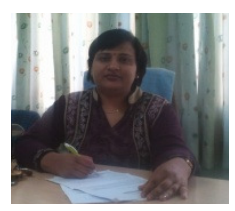
Conferences And Journals.

Dr Neena Gupta is working as Associate Professor at PEC University of Technology in Electronics and Electrical Communication Engineering Department. Her areas of interest are Communication, Optical/ Mobile, Wireless Communication, Digital Electronics. She is a member of IEEE and few other organizations. 